\title{
IMPLEMENTAÇÃO DE POLÍTICAS EDUCACIONAIS E EQUIDADE: REGULAÇ̃̃O E MEDIAÇÃO
}

Vanda Mendes Ribeiro'

(D) Alicia Bonamino"

(D) Sergio Martinic ${ }^{\prime \prime \prime}$

\footnotetext{
l Universidade Cidade de São Paulo (Unicid), São Paulo (SP), Brasil; vandaribeiro2@gmail.com

" Pontifícia Universidade Católica do Rio de Janeiro (PUC-Rio), Rio de Janeiro (RJ), Brasil; alicia@puc-rio.br

"' Universidad de Aysén (UAY), Aysén, Chile; sergio.martinic@uaysen.cl
}

\section{Resumo}

Este artigo discute o modelo de regulação de duas iniciativas de justiça como equidade na escola. Referências sobre implementação de políticas públicas, ação pública e regulação dos sistemas de ensino geraram categorias a priori. Os dados analisados vieram de entrevistas com dirigentes, gestores e professores. Sua interpretação baseou-se na análise de conteúdo. Conclui-se que as duas iniciativas são regidas por modelos de regulação similares, instituindo vigilância sobre ações e interações dos dirigentes e agentes implementadores, mesclando medidas educativas dos tipos burocrático e pós-burocrático. Esse modelo incorpora instrumentos, técnicas e ferramentas que implicam os atores nos objetivos prescritos, na presença de tensões, denotando capacidade de incidir nas práticas cotidianas.

\section{POLÍTICAS PÚBLICAS • EDUCAÇÃO • DESIGUALDADE • JUSTIÇA}

\section{IMPLEMENTATION OF EDUCATIONAL POLICIES AND EQUITY: REGULATION AND MEDIATION}

\begin{abstract}
The present article addresses the regulation model of two Law initiatives as equity in school environment. References about the implementation of public policies and actions, and the regulation of teaching systems account for the generation of categories, a priori. The assessed data were collected during interviews carried out with school principals, managers and teachers. Data interpretation was based on content analysis. In conclusion, both initiatives were guided by similar regulation models, they lied on monitoring the actions and interactions of school principals and implementation agents by mixing bureaucratic and post-bureaucratic education measures. These models encompass instruments, techniques and tools that imply actors' involvement in the prescribed goals and in solving distress cases to highlight their ability to influence daily routines.
\end{abstract}

PUBLIC POLICIES • EDUCATION • INEQUALITY • JUSTICE 


\section{IMPLEMENTACIÓN DE POLITTICAS EDUCACIONALES Y EQUIDAD: REGULACIÓN Y MEDIACIÓN}

\section{Resumen}

Este artículo discute el modelo de regulación de dos iniciativas de justicia como equidad en la escuela. Referencias sobre implementación de políticas públicas, acción pública y regulación de los sistemas de enseñanza, generaron categorías a priori. Los datos analizados vinieron de entrevistas a dirigentes, gestores y profesores. Su interpretación se basó en el análisis del contenido. Se concluye que las dos iniciativas son regidas por modelos de regulación similares, instituyendo vigilancia sobre acciones e interacciones de los dirigentes y agentes implementadores, mezclando medidas educativas de los tipos burocrático y postburocrático. Ese modelo incorpora instrumentos, técnicas y herramientas que implican los actores en los objetivos prescritos, en la presencia de tensiones, denotando capacidad de incidir en las prácticas cotidianas.

POLÍTICAS PÚBLICAS • EDUCACIÓN • DESIGUALDADE • JUSTICIA

\section{LA MISE EN OEUVRE DE POLITIQUES ÉDUCATIVES ET ÉQUITÉ: RÉGULATION ET MÉDIATION}

\section{Résumé}

Cet article traite du modèle de régulation de deux initiatives de justice visant l'équité à l'école. Des références concernant la mise en ouvre de politiques publiques, de l'action publique et de la réglementation des systèmes éducatifs ont généré des catégories a priori. Les données analysées proviennent d'entretiens avec des dirigeants, des gestionnaires et des enseignants. L'interprétation s'appuye l'analyse de contenu. La conclusion est que les deux initiatives sont régies par des modèles de régulations similaires qui établissent un contrôle sur les actions et les interactions des dirigeants et des agents de l'exécution, en associant des mesures éducatives bureaucratiques et post-bureaucratiques. Ce modèle intègre des instruments, des techniques et des outils qui impliquent les acteurs dans les objectifs prescrits, même en présence de tensions, ce qui indique sa capacité d'affecter les pratiques quotidiennes. 
STE ARTIGO TEM POR OBJETIVO DISCUTIR O MODELO DE REGULAÇÃO DE DUAS INICIATIVAS governamentais - a política de educação para os anos iniciais do ensino fundamental de Marília, município do estado de São Paulo, e o Programa de Alfabetização na Idade Certa (Paic), do estado do Ceará - que conseguiram, segundo evidências de pesquisa, num período de tempo, resultados em termos de justiça como equidade na escola. Recentemente, em 2018, a Constituição Federal completou 30 anos. O art. 205 define a educação básica como um direito social universal, a ser garantido a todos, independentemente da origem social, raça, cor, idade, ou qualquer forma de discriminação. Para garantir o exercício desse direito, a Constituição discrimina, através do art. 211, encargos e competências da União, dos estados e dos municípios (BRASIL, 1988). Para viabilizar o princípio da equidade presente na definição da educação como direito de todos, a Constituição define os percentuais da receita de impostos a serem aplicados pelos entes federados na manutenção e no desenvolvimento do ensino (arts. 22, 24, 30, 208 e 212). Além disso, a Lei de Diretrizes e Bases da Educação Nacional (LDBEN), n. 9.394 (BRASIL, 1996), determina, no art. 22, "igualdade de condições para o acesso e permanência na escola" e "garantia de padrão de qualidade", e estabelece o financiamento da educação básica pelo Fundo de Manutenção e Desenvolvimento do Ensino Fundamental e de Valorização do Magistério (Fundef) e pelo Fundo de Manutenção e Desenvolvimento da Educação Básica (Fundeb).

A noção de equidade presente na legislação educacional pode ser interpretada à luz de Dubet (2009), que defende, para a educação básica, num raciocínio rawlsiano, um princípio de justiça que garanta uma determinada distribuição do conhecimento, ou seja, a educação de base. Segundo esse princípio, as políticas educacionais devem atuar para que todos, inclusive aqueles com maior dificuldade ou menos favorecidos socialmente, possam galgar o conhecimento que se define como necessário na referida etapa da escolaridade, remetendo-nos à noção de justiça como equidade utilizada neste texto (RIBEIRO, 2014).

Crahay (2000) considera que a equidade na escola é possível graças à ação pedagógica e à regulação da ação dos professores por meio do dispositivo que denominou "sistema de pilotagem", isto é, uma forma de acompanhamento da escola, de seus processos pedagógicos e avaliação dos resultados de aprendizagem para realizar correções. Visando a incidir sobre as desigualdades, propõe a possibilidade de discriminação positiva nas escolas, contrariando a tendência da reprodução da desigualdade (BOURDIEU; PASSERON, [1975]).

Pesquisas denotam experiências de políticas públicas que visaram a implementar os direitos estabelecidos na Carta Constitucional e que, em meio às tensões próprias da implementação das políticas públicas voltadas à distribuição de bens sociais valorizados, conseguiram resultados de equidade: é o caso da política educacional do município de Marília, São Paulo, para os anos iniciais do ensino fundamental, estudada por Ribeiro (2012), e do Paic, estudado por Kasmirski, Gusmão e Ribeiro (2017), Padilha et al. (2013), Vieira e Vidal (2013), Koslinski, Ribeiro e Oliveira (2017), Correa (2018), Mota (2018), Bonamino et al. (2019) e Cruz, Farah e Ribeiro (2020). Desses estudos, apenas Ribeiro (2012) discutiu sob que modelo de regulação a política educacional de Marília era regida. Este estudo pretende ampliar a discussão sobre a interface entre modelo de regulação e equidade. 


\section{FUNDAMENTAÇÃO TEÓRICA}

\section{TOMADA DE DECISÃO E IMPLEMENTAÇÃO DA POLÍTICA PÚBLICA}

Lipsky (2010), em seus estudos sobre a atuação de agentes implementadores, constatou que esses agentes são mediadores entre o Estado e a população. Embora submetidos a normas, podem recorrer a sanções ou selecionar beneficiários segundo seus critérios de merecimento, interferindo nas decisões políticas. O autor ressalta que esses trabalhadores fazem uso de discricionariedade, podendo determinar a natureza, a quantidade e a qualidade dos benefícios. Giusto e Ribeiro (2019), analisando estudos de implementação de políticas públicas, explicitam outros fatores intervenientes: contextos, condições de trabalho, padrões de interações entre os agentes implementadores, suas diversas interpretações decorrentes dos processos de comunicação, treinamentos e também suas crenças, interesses e valores pessoais. A multiplicidade de fatores que, segundo a literatura, interferem na implementação das políticas públicas questiona a racionalidade normativa ou a aplicação "top-down” de políticas que têm objetivos de equidade na ação pública.

\section{A SOCIOLOGIA DAS REGULAÇÕES: MEDIAÇÃO DAS INTERAÇÕES NA IMPLEMENTAÇÃO DA POLÍTICA EDUCACIONAL}

O problema da assimetria entre o desenho da política educacional e sua implementação na escola tem sido abordado pela Sociologia das Regulações. Maroy (2008) define os modos de regulação institucional do sistema educacional como o conjunto de mecanismos de orientação, interpretação e controle que permitem a coordenação de professores, gestores, estudantes e famílias nos níveis do sistema educacional. A regulação é, segundo esse autor, realizada por processos, atores e contextos de ação, por vezes contraditórios, que entrecruzam níveis macro e micro, e englobam negociações, transações e arranjos institucionais, estruturando a coordenação do sistema. Para Maroy (2008), a implementação contabiliza um sistema de inter-relações, compromissos, arranjos e articulações em diferentes níveis, cenários e campos, e entre diferentes atores e sistemas de ação. Pesquisadores afirmam que as reformas e as políticas são sistemas de ação social e coconstrução entre vários atores, em que ideias, crenças, valores e conhecimentos desempenham um papel central (MULLER, 2000; DRAELANTS; MAROY, 2008).

Nessa perspectiva, Barroso (2005) adota o conceito de regulação enquanto modo de coordenação dos sistemas de ensino ou forma de governança. Para esse autor, na regulação, há instâncias de mediações, traduções, passagens de fluxos que desempenham papel essencial, tal como "nós" numa rede; afirma ainda não ser possível prever o sucesso das estratégias prescritas nas normas, razão pela qual, na regulação, há medidas de política educativa para lidar com a situação de desequilíbrio entre a norma e a ação.

Lascoumes e Les Galès (2012, p. 22) afirmam que instrumentos, técnicas e ferramentas têm importante papel na articulação dos atores em torno de objetivos comuns. Os instrumentos representam um dispositivo técnico que possui uma concepção própria de regulação e tem capacidade de orientar e tornar previsível o comportamento dos atores. O censo demográfico seria um exemplo de instrumento dessa perspectiva. Os instrumentos se realizam por meio do uso de técnicas e ferramentas. As técnicas são um "dispositivo concreto que operacionaliza o instrumento"; por exemplo, uma das categorias estatísticas do censo, como raça/cor. Já as ferramentas representam "um micro dispositivo dentro de uma técnica”, como pode ser ilustrado por uma fórmula para o cálculo de um índice de desigualdade social.

\section{REGULAÇÃO DOS SISTEMAS DE ENSINO NO BRASIL: UMA DISCUSSÃO EXPLORATÓRIA}

Maroy $(2004,2008,2011)$ e Barroso (2005) apontam o surgimento recente, na Europa, de novas formas de "governança" pós-burocráticas dos sistemas de ensino "Estado avaliador" e "quase mercado”. Nesses modelos, a governança se realizaria em torno de documentos curriculares centralizados 
e pelo controle do desempenho dos alunos, medido por avaliação externa, com autonomia pedagógica e financeira das escolas. Metas são negociadas e cobradas.

O estudo do Centro de Estudos e Pesquisas em Educação, Cultura e Ação Comunitária (Cenpec) realizado para a Fundação Vitor Civita (BATISTA et al., 2015) sobre políticas curriculares dos estados brasileiros e do Distrito Federal mostra que políticas educacionais têm recorrido tanto a estratégias de regulação do tipo pós-burocrático como do tipo burocrático. Denota haver no país experimentações de governança visando ao que os gestores denominam melhoria da qualidade da educação, uma noção vinculada às políticas de avaliações externas.

Segundo o estudo do Cenpec, nos estados, há

[...] foco no controle dos resultados educacionais, com definição de metas, mas buscando garantir também o controle do processo de ensino e aprendizagem. [...] não há foco na autonomia pedagógica, conforme preveem os dois modelos de regulação pós-burocrática, apresentados por Maroy $(2008,2013)^{1}$ e Barroso (2005). (BATISTA et al., 2015, p. 63)

Experiências internacionais mostram outros países que adotam novas formas de regulação, segundo seus contextos e realidades, dando origem a distintos tipos de governança com modelos híbridos que integram, com graus variados de importância, o modelo pós-burocrático, como tem sido documentado em países europeus (MAROY, 2008; BARROSO, 2005) e no Chile, entre outros (BELLEI, 1988, MARTINIC; ELACQUA, 2010).

\section{A IMPORTÂNCIA DO CONTEXTO NA IMPLEMENTAÇÃO DA POLÍTICA PÚBLICA}

Quando uma política pública gera equidade, supõe-se que os interesses pesem sobremaneira na implementação, uma vez que implica mudanças nos critérios de distribuição de bens sociais valorizados para que beneficiem os desfavorecidos. Santos (1979) publicou pesquisa sobre a evolução das políticas sociais no Brasil, discutindo a equidade. Embora não fale de regulação, destaca a relevância da mediação de conflitos no processo de concretização das políticas. Segundo o autor, a implementação de políticas públicas que gera equidade advém de decisão política, e esta, por sua vez, é dependente de fatores como o comportamento das elites políticas, a força política da instituição implementadora (ter ou não mais acesso a recursos, por exemplo, pode gerar maior ou menor poder), o conhecimento e as intencionalidades que essas elites têm, a estrutura de escassez (referente aos recursos orçamentários e à qualidade dos recursos físicos e humanos), os conflitos entre grupos e a sua mediação, a burocracia estatal e sua força política e também situações demográficas.

Pode-se afirmar que as regulações e suas medidas de políticas, frente ao desafio da equidade, estão estreitamente relacionadas aos contextos, medidas educativas, trajetória e dinâmica dos atores intervenientes. Por isso, torna-se relevante estudá-las, para que possamos compreender suas particularidades.

\section{OBJETO DE ESTUDO E PROCEDIMENTOS METODOLÓGICOS}

\section{AS INICIATIVAS GOVERNAMENTAIS ESTUDADAS: ANOS INICIAIS DO ENSINO FUNDAMENTAL (EF1)}

As duas iniciativas governamentais estudadas foram implementadas em sistemas educacionais de esferas administrativas e contextos geográficos distintos. A primeira é uma política municipal desenvolvida no município de Marília, enquanto a segunda é uma iniciativa desenvolvida na

1 MAROY, C. L'école à l'épreuve de la performance: les politiques de régulation par les résultats. Louvain-la-Neuve: De Boeck, 2013. (Perspectives en Éducation et Formation). 
rede estadual do Ceará. A priori, sabe-se que a aproximação das duas experiências se efetiva pelo foco no EF1, por terem alcançado resultados educacionais equitativos e pela inexistência de rupturas num período de mais de dez anos.

A política educacional de Marília constitui-se por medidas educativas pedagógicas e de estruturação organizacional que se estenderam por cerca de dez anos e que, segundo os entrevistados e as evidências estatísticas apresentadas por Ribeiro (2012), influenciaram os resultados educacionais alcançados por volta de 2010 ou 2011.

O Paic tem origem em uma mobilização da sociedade civil, em 2005. Oficialmente lançado como política pública e institucionalizado por meio da Lei n. 14.026, em 2007, com foco no segundo ano do EF1 ${ }^{2}$, visava ao estabelecimento de condições necessárias para que os alunos chegassem ao $5^{\circ}$ ano sem distorção idade-série e com o domínio das competências de leitura, escrita e cálculo adequados à sua idade e ao seu nível de escolarização.

O Paic instituía que o estado, em cumprimento ao regime de colaboração, poderia prestar cooperação técnica e financeira aos municípios cearenses, com vistas à melhoria dos seus resultados de aprendizagem. O programa se organizou inicialmente em cinco eixos: a) Gestão Municipal; b) Alfabetização; c) Formação do Leitor; d) Educação Infantil; e e) Avaliação Externa. A Coordenadoria de Cooperação com os Municípios para Desenvolvimento da Aprendizagem na Idade Certa (Copem) da Secretaria da Educação do Estado do Ceará (Seduc) atua por meio de 20 Coordenadorias Regionais de Desenvolvimento da Educação (Crede), nas quais foram implantados os Núcleos Regionais de Cooperação com os Municípios (NRCOMs). De acordo com Gusmão e Ribeiro (2011), a organização do Paic compreendeu equipes municipais responsáveis pelas orientações às escolas que, lideradas por um gerente, seguem divisão similar à da Copem: três ou mais pessoas, a depender do tamanho do município e da estrutura da Secretaria Municipal de Educação (SME).

\section{LOCALIDADES E REDES DE ENSINO ONDE AS INICIATIVAS FORAM DESENVOLVIDAS}

O município de Marília encontra-se no estado de São Paulo. Em 2010, momento da coleta dos dados usados neste artigo, o município tinha uma população de 216.745 habitantes.

Nos anos iniciais do EF1, em 2011, a rede municipal de Marília respondia por 58\% das matrículas (7.707 alunos), e a taxa de escolarização bruta, para pré-escola, era de 95\%, em 2010, segundo o Censo Escolar (RIBEIRO, 2012). No Brasil, era de 62,5\%. A taxa bruta de escolarização em creche era de $47 \%$ nesse município. O autor informou ainda que, no ano de 2010, segundo o Instituto Nacional de Estudos e Pesquisas Educacionais "Anísio Teixeira" (Inep), a taxa de aprovação nos anos iniciais do EF1, na rede municipal analisada, era de quase $100 \%$; a de abandono, quase $0 \%$; a distorção idade-série era de $4 \%$ (enquanto a média do estado de São Paulo era de 14\%). A reprovação era de $4 \%$ em 2001, seu maior patamar no período, e decresceu para cerca de 2\%, assim permanecendo até 2010. Em 2005, o Índice de Desenvolvimento da Educação Básica (Ideb) para os anos iniciais do EF1 da rede municipal de Marília era, segundo Ribeiro (2012), de 5,4, e passou a 6,4 em 2009. Em 2017, o site do Inep indica que o Ideb alcançou 7,2.

O estado do Ceará, um dos nove estados da região Nordeste, possui 184 municípios, distribuídos em um território de mais de $148 \mathrm{mil} \mathrm{km²}$. O estado possui cerca de 8,5 milhões de habitantes. A maior parte da população $(75,1 \%)$ habita as áreas urbanas, sendo que mais da metade $(52,4 \%)$ se concentra na Região Metropolitana de Fortaleza. Em 2005, o Índice de Desenvolvimento Humano (IDH) do estado era 0,764, menor que o índice brasileiro (0,795), mas maior que o da região Nordeste (0,720) (CEARÁ, 2012).

2 Posteriormente, alterado pela Lei n. 15.921, de 15 de dezembro de 2015, o Paic se transformou no Mais Paic, estendendo a ação do programa para todo o EF, o que implicou mudanças nos eixos de ação. Neste artigo, analisaremos somente o Paic. 
Segundo documento da Secretaria de Educação do Ceará (2012), em 2009, havia no estado 9.913 estabelecimentos de educação básica, sendo 49\% situados em áreas urbanas, 37 escolas em áreas indígenas e 22 em áreas remanescentes de quilombos. Nesse mesmo ano, também segundo o documento, o estado contava com 2.567.230 matrículas na educação básica, sendo 370.975 (14,5\%) na educação infantil e 1.550 .930 (60,5\%) no ensino fundamental. Para a faixa etária de 4 a 6 anos, em 2009, a taxa de escolarização da população no estado era maior que a do Brasil e a da região Nordeste (90,7\%, contra $74,8 \%$ no Brasil e $81,4 \%$ no Nordeste). Na faixa dos 6 a 14 anos, nesse mesmo ano, a taxa do estado ficava um pouco acima da observada para o país e para o Nordeste, e, na de 15 a 17 , um pouco abaixo da taxa do Brasil e quase igual à do Nordeste (98,3\% no Ceará, 97,4\% no Nordeste e 97,6 no Brasil) (CEARÁ, 2012). Sobre a taxa de reprovação nos anos iniciais do ensino fundamental, enquanto "o país caiu 2,0 pontos entre 2005 e 2009 e o Nordeste 2,5, o estado em questão diminuiu 3,6 pontos na taxa de reprovação" (CEARÁ, 2012, p. 46).

Cruz, Farah e Ribeiro (2020) afirmam que 17,1\% da população do estado vivia em situação de extrema pobreza em 2010, uma taxa mais alta que a do Brasil (8,5\%), e que, no ano de 2010, 77,1\% dos domicílios cearenses tinham rendimento de até um salário mínimo. No Brasil, esse dado era de 56,4\%. Segundo os autores, em 2016, 39,83\% da população cearense era beneficiária do Bolsa Família.

\section{OS DADOS UTILIZADOS NESTE TEXTO}

Os dados que configuram a política educacional do município Marília derivam de entrevistas feitas com agentes implementadores das políticas de nível macro e micro (dirigentes, técnicos da Secretaria da Educação e gestores escolares de uma escola) e encontram-se consubstanciadas em tese defendida por um dos autores deste artigo (RIBEIRO, 2012). ${ }^{3}$ Essa tese pôde contar com dados levantados por uma pesquisa mais ampla sobre redes de ensino denominada "Pesquisa Bons Resultados no Ideb: estudo exploratório de fatores explicativos", coordenada por professores da Faculdade de Educação da Universidade de São Paulo (FE/USP).

Na tese indicada, com base nos microdados da Prova Brasil 2007, foram pesquisadas duas redes municipais com mais de cinco mil matrículas nos anos iniciais do EF1 do estado de São Paulo. Por meio de análise de cluster - que combinou coeficiente de variação da nota de matemática, média do nível socioeconômico (NSE) dos alunos e média das proficiências dos alunos observou-se que havia, no estado, quatro grupos de redes de ensino com mais de cinco mil matrículas, sendo que um deles apresentava 19 com uma distribuição de ensino mais equitativa nos anos iniciais do EF1, sendo uma delas o município analisado neste artigo. O percentual de alunos no tercil de NSE mais baixo no quinto ano, nessa rede, em 2007, que obtiveram proficiência adequada em Matemática (225 na escala Saeb) foi de 41\%, enquanto a média no grupo de redes mais equitativas do estado era de 31\%. Da mesma forma, 39\% do total de alunos das redes mais equitativas tinham proficiência acima de 225 , e, no município aqui analisado, $49 \%$. No grupo de redes menos equitativas, apenas $21 \%$ dos alunos alcançavam o nível adequado de proficiência.

A partir desses dados, a política educacional da rede de ensino do município de Marília se constituiu em um caso a ser estudado para se compreender o que lhe era "singular". A pesquisa caracterizou três dos processos de implementação da política em questão: 1) planejamento; 2) avaliação; e 3) acompanhamento da aprendizagem. Obteve, ainda, informações sobre formação de professores e currículo. Foram feitas entrevistas com dirigentes da educação, agentes implementadores da Secretaria e das escolas e observação da infraestrutura e do organograma dessa Secretaria e de uma escola, além de coleta e análise de documentos.

3 Nessa tese é possível encontrar uma descrição mais detalhada da política implementada em Marília e de suas estratégias de implementação. 
Os dados sobre o Paic foram obtidos em 22 entrevistas realizadas entre 2018 e 2019 com dirigentes, gestores e ex-gestores da Secretaria Estadual de Educação do Ceará e com gestores escolares e professores de duas escolas de Fortaleza. O interesse para essa pesquisa nasceu de estudos que notificaram a ampliação da equidade no EF1 no Ceará: Padilha et al. (2013) afirmaram que os resultados educacionais do estado melhoraram mais nas escolas de municípios com menor inserção econômica, e Kasmirski, Gusmão e Ribeiro (2017) concluíram que os alunos com menor nível socioeconômico do estado do Ceará aumentaram mais sua proficiência entre 2007 e 2013, sendo o Paic responsável por parte desse efeito de equidade.

\section{CATEGORIAS DE ANÁLISE A PRIORI}

Os dados foram investigados, sob inspiração da análise de conteúdo (BARDIN, 1977), classificando as mensagens tendo em vista as seguintes categorias a priori, advindas do referencial teórico:

- Contexto de implementação e condicionalidades:

$\checkmark$ poder dos dirigentes para tomadas de decisões;

$\checkmark$ intencionalidade/interesse das elites dirigentes;

$\checkmark$ capacidade técnica de dirigentes e agentes implementadores.

- Regulação nas escolas/redes de ensino: mediação das interações e coordenação das ações:

$\checkmark$ instrumentos, técnicas e ferramentas;

$\checkmark$ tensões, conflitos e espaços de negociação.

- Modelo de regulação das iniciativas estudadas:

$\checkmark$ acompanhamento das escolas pelos órgãos dirigentes;

$\checkmark$ currículo;

$\checkmark$ uso dos resultados de avaliação externa.

\section{ANÁLISE}

\section{CONTEXTO DE IMPLEMENTAÇÃO E CONDICIONALIDADES}

Nas duas iniciativas estudadas, há "proteção" do chefe do Executivo às tomadas de decisão pelos dirigentes da educação. Essa proteção reforça a autonomia e o poder desses dirigentes para lidar com os interesses de vereadores, deputados e outros atores da política local, sem ter que "desvirtuar" sobremaneira os objetivos estabelecidos.

A secretária da Educação do município de Marília informou que o prefeito protege a área da Educação das interferências políticas:

O prefeito apoia as decisões da gente também. Se não fosse isso... [...] Além da gente ter a liberdade de dizer ao prefeito que a coisa não é bem assim, muitas vezes você pode tomar uma determinada ação que o prefeito pode não concordar com você, mas vai apoiar. E quando você diz "não" para um vereador - e eu digo "não" para vereador sim -, eu sempre digo um não respaldado: "não posso te atender por isso e isso". (RIBEIRO, 2012, p. 439)

De acordo com o ex-secretário adjunto da Educação do Ceará (gestão de 2007 a 2015) e com a agente implementadora de nível macro, ex-coordenadora da Copem (de 2007 a 2014), a equipe do Paic foi montada sem ter que aceitar ingerência política na indicação dos cargos, devido à proteção do governador.

A Copem e o Paic também se beneficiaram de uma decisão que foi assim: as equipes da Secretaria de Educação são montadas seguindo uma lógica do compromisso e de resultado no trabalho. E não a lógica do "você foi 
indicado por fulano ou sicrano, ou pelo vereador, deputado ou irmão do político $A$ ou $B$ ". (Ex-secretário adjunto da Educação do Ceará, gestão de 2007 a 2015)

[...] ele nunca interveio na Secretaria para dizer "bote fulano, tire sicrano", nunca mexeu com a nossa equipe, ele sempre foi aquela pessoa para apoiar aquilo que fosse o certo, que fosse apoiar o que era necessário para fazer o trabalho acontecer. Então ele bancou politicamente tudo o que foi necessário. (Ex-coordenadora da Copem, de 2007 a 2014)

No que se refere à capacidade técnica para a administração da educação, nas duas iniciativas são detectados agentes implementadores e dirigentes de nível macro com experiência na gestão da educação, com formação em nível superior. $\mathrm{O}$ assessor que coordenava a dimensão pedagógica da rede municipal de Marília afirmou poder contar com produção de conhecimento interna à rede: "os cursos que nós temos oferecido de formação em serviço [...] foram elaborados por essa equipe! Então nós já atingimos um patamar que a própria equipe vai buscar e traz para os professores”. A secretaria, segundo o entrevistado, dá preferência aos profissionais da rede para preencher cargos de orientação pedagógica nas escolas:

Nós conseguimos montar aqui na Secretaria da Educação uma equipe pedagógica formada por profissionais da própria rede municipal. Professores de carreira que se destacaram no trabalho na escola e que nós pensamos "puxa, esse cara é bom, vou trazer ele para cá". Eles conhecem realmente as necessidades, nós falamos profissionais do "chão da escola". (RIBEIRO, 2012, p. 445)

A tese de Ribeiro (2012, p. 445) indica que a secretária de Educação de Marília tem nível superior, especialização em gestão pública e foi diretora na rede. É graduada em Educação Física e Pedagogia, ingressou na rede municipal de ensino como diretora, via concurso público, e está na sua terceira gestão, ocupando o cargo de secretária há dez anos. O prefeito tem nível superior em Pedagogia e foi professor da rede. A secretária da Educação já foi da diretoria da União Nacional dos Dirigentes Municipais de Educação (Undime). O assessor principal trabalhou durante 31 anos na rede de ensino estadual. Foi professor, diretor, supervisor e delegado de ensino. É também professor na universidade local: “Trabalho há 15 anos e dou aula no curso de Pedagogia. A minha formação acadêmica é professor primário, e eu tenho mestrado em Educação. A experiência desde o magistério são 41 anos" (RIBEIRO, 2012, p. 446).

No caso do Ceará, entrevistas realizadas com três dirigentes da Secretaria do Estado e 12 técnicos e ex-técnicos da Copem denotaram que os dirigentes eram professores universitários que atuaram na experiência de Sobral, e que os técnicos, profissionais das redes de ensino que passaram a atuar na implementação do Paic, por convite, depois de terem se destacado em atuações (como professores, coordenadores pedagógicos, superintendentes, secretários de educação, técnicos de Crede e de secretarias) que lhes deram experiência de gestão e conhecimento correlato às funções que assumiram.

Observou-se ainda como traço comum das duas experiências a intencionalidade das elites dirigentes para a melhoria da qualidade da educação e o foco na alfabetização na idade certa. A secretária da Educação do município de Marília relatou que seu foco é a:

Melhoria da qualidade de ensino. Só que, para que a gente possa chegar numa qualidade de ensino que foque realmente para que a criança tenha seu conhecimento, [...] temos vários fatores [...]. Passa pela questão de acesso, e esse acesso, na minha concepção, vai de transporte escolar para a criança 
que necessita, ao acesso para a criança que tem dificuldade de aprendizagem ou alguma deficiência, [e também à] inclusão de todos dentro da educação. [...] Foco na alfabetização, em primeiro lugar. Se a criança for alfabetizada na idade correta, no que ela tem realmente que aprender na idade certa, não tem distorções na série, não tem Educação de Jovens e Adultos, e o aprendizado ocorre de maneira muito mais tranquila. (RIBEIRO, 2012, p. 447)

A dirigente estadual cearense de nível macro (gestão de 2007 a 2014) afirmou que o programa nasceu como política pública, baseado em diagnóstico e em experiências concretas, para incidir sobre o problema do analfabetismo escolar.

\begin{abstract}
E nós tínhamos a experiência de Sobral, no enfrentamento ao analfabetismo escolar, como realidade que nós constatamos, no caso de Sobral, em 2001, e também já tinha acontecido o comitê na Assembleia Legislativa, que tinha sido implantado quando o Ivo foi para a Assembleia Legislativa como deputado estadual. Ele fez uma proposição à mesa diretora da Assembleia de instalar o Comitê Cearense pela Eliminação do Analfabetismo Escolar, quer dizer, esse Comitê, eu considero que foi uma semente muito importante do Paic. [...] Foi um processo de chamamento, convite aos municípios para uma adesão, no primeiro momento fizemos alguns combinados em relação a avaliação que seria feita, o desafio mesmo que nos movia, que era garantir o sucesso da alfabetização dos alunos, das crianças na idade certa.
\end{abstract}

\title{
REGULAÇÃO NAS ESCOLAS/REDES DE ENSINO: COORDENAÇÃO DE AÇÕES E INSTRUMENTOS
}

Nas duas iniciativas, pode-se afirmar que a avaliação externa e o currículo centralizado e detalhado utilizados em todas as escolas são instrumentos no sentido do conceito proposto por Lascoumes e Les Galès (2012): orientam e tornam mais previsíveis a ação dos agentes implementadores. Em torno desses instrumentos são incorporadas, nas redes de ensino, variadas técnicas e ferramentas. No município estudado, os dados indicam que o planejamento também pode ser considerado um instrumento que congrega ferramentas e técnicas.

A avaliação externa no Paic faz uso de exames bimestrais, um dispositivo (técnico) que concretiza na escola a avaliação externa, visando à vinculação de todos pela busca de desempenho dos alunos. A avaliação externa, enquanto instrumento, explicita também sua ferramenta central: a medida padrão de desempenho do aluno a ser alcançada e que relaciona o conteúdo a ser ensinado e o que deve ser aprendido. O material didático estruturado pode ser compreendido como mais uma técnica, que concretiza o instrumento "currículo". No bojo dessa técnica, a mesma ferramenta dos exames bimestrais se coloca: o que todos os professores ensinam no dia a dia para que a medida padrão de desempenho seja alcançada.

A gente vê as questões que os alunos mais erraram e acertaram para ter uma ideia do que eles já dominam e do que eles ainda precisam dominar. Além disso, a gente também vê os alunos que, de modo geral, tiraram boas notas e alunos que não tiraram boa nota. Então a gente tem uma ideia do aluno que está com mais dificuldade... (Professora do quinto ano, escola 2)

Os dados mostram visitas às escolas, uma técnica que visa a vincular a formação oferecida no programa aos resultados de aprendizagem, medidos pela avaliação externa. Essas visitas ocorrem em cadeia: da Copem às Crede, das Crede aos municípios, e destes às escolas. A agente implementadora de nível macro, orientadora da célula de gestão do Paic na Copem, afirma a visita como técnica de apoio e verificação das necessidades: 
[...] quando estava na Crede, fazia visitas [aos municípios] e eu via a realidade, o que estavam precisando. [...] Depois da formação [que reúne os formadores das Crede], a equipe aqui da Copem vai fazer a visita em cada Crede... E eles acompanham as formações que estão acontecendo lá para saber se elas estão sendo repassadas de acordo com o que foi planejado.

A burocrata cearense de nível macro, da Copem, relatou que

[...] essa parte da visitação do estado e de colaboração forte com as escolas, é a Crede que tem que fazer. Nós também acompanhamos... A Crede visita. A gente vai também. Em 2017 eu visitei muitas escolas. A gente mapeia [aqueles que precisam mais devido aos resultados].

Ou seja, a cadeia acima exposta, que define o modo de visita às escolas, pode ser quebrada, e visitas diretas da Copem aos municípios podem ocorrer, quando se observa que não estão conseguindo avançar em seus resultados na avaliação externa, evidência da força da ferramenta "medida padrão do desempenho dos alunos" para colocar os agentes implementadores frente a objetivos comuns. Alguns municípios cearenses, como Fortaleza e Sobral, contam com superintendentes para acompanhar as escolas. Esse acompanhamento busca explicitar para os gestores escolares a relação entre a prescrição estabelecida nos instrumentos (proposta curricular, avaliação externa), os resultados (advindos da avaliação externa) e formas de agir visando a melhorar os resultados.

No município analisado, Ribeiro (2012, p. 277) informa que, segundo a secretária de Educação: "tem um plano de trabalho que é feito, cada escola tem o seu projeto político pedagógico, tem suas metas a alcançar. Esse trabalho é acompanhado sistematicamente pela equipe da Secretaria: são visitas constantes às escolas”. Essas visitas constantes, segundo Ribeiro (2012, p. 294), foram também relatadas por técnico da Secretaria: "E tem as visitas que nós fazemos com o assessor principal intervindo justamente nessas questões que precisam ser trabalhadas dentro da escola”. As visitas foram incorporadas como técnica também nas escolas, do coordenador pedagógico às salas de aula. A coordenadora pedagógica da Escola de Municipal de Ensino Municipal (Emef) pesquisada nesse município afirmou que seu trabalho é organizado por meio de uma agenda semanal e inclui a realização de "visitas às salas de aula; a cada semana, uma série" (RIBEIRO, 2012, p. 298).

De acordo com a tese de Ribeiro (2012, p. 278), o planejamento das escolas contempla "a organização do tempo do professor em sala de aula”. A técnica adotada para efetivar essa vinculação é chamada de "semanário". O semanário é elaborado pelo professor e inclui avaliação do que foi planejado na semana anterior - o que foi e o que não foi realizado e suas razões - e o plano para a semana seguinte. O papel dos coordenadores pedagógicos se desenvolve fundamentalmente em torno do que essa técnica permite vislumbrar sobre o ensino e a aprendizagem, uma vez que ela permite observar o que já foi executado em relação ao plano geral, as estratégias mais profícuas usadas pelos professores e as dificuldades principais. O assessor principal informa que "todos os professores fazem o planejamento semanal. Chama-se semanário. E nós coordenamos [...], em sintonia. No semanário existe a questão da expectativa em relação aos alunos, os conteúdos, atividades e avaliação. Isso tem em toda a rede". Observa-se que as ferramentas centrais que compõem essa técnica abrangem uma definição de tempo de ensino para o professor e também de expectativa de aprendizagem para os alunos. A secretária de Educação corrobora essa interpretação, afirmando que os semanários organizam o tempo do professor em torno da expectativa de aprendizagem para os alunos:

Uma coisa que eu acho fundamental é a organização do tempo do professor em sala de aula. Então todos os professores fazem semanário. Éa organização semanal, e isso vocês vão poder observar lá na escola. Peçam para ver os semanários dos professores. Então a função primordial do professor 
coordenador é de trabalhar o semanário junto com o professor. Naquela semana que foi prevista, o professor realmente colocou e focou todos os conteúdos que são necessários? Ele fez uma avaliação do que aconteceu na semana anterior? Ele reprogramou aquilo que não foi possivel [realizar]? O que ele está trabalhando está condizente com a sua turma? O que realmente a sua turma precisa aprender? A sua turma tem alunos com dificuldades?

Nas duas experiências, observa-se uma organização administrativa que permite a coordenação dos agentes implementadores por meio de técnicas e ferramentas que se consubstanciam na relação com o planejamento (no caso do município), com a avaliação externa e com o currículo estruturado (nas duas iniciativas). Técnicas como visitas de supervisão e orientação às escolas e às salas de aula visam a unir a ferramenta de medida do desempenho dos alunos, o currículo e a ação dos agentes implementadores.

A experiência do Ceará se distingue por envolver todos os seus municípios num regime de colaboração com o estado (CEARÁ, 2012). Para incidir sobre os interesses dos agentes implementadores e dos dirigentes municipais, como os prefeitos, adotou-se alguns incentivos que também podem ser compreendidos enquanto instrumentos na perspectiva de Lascoumes e Les Galès (2012). A forma como se passou a distribuir a quota-parte de $25 \%$ do Imposto sobre Circulação de Mercadorias e Serviços (ICMS) é um deles. Essa quota, que diz respeito ao percentual que o estado distribui aos municípios, ficou, por legislação, atrelada ao resultado de políticas educacionais, da saúde e do meio ambiente. Dos $25 \%$, $18 \%$ estão atrelados aos resultados educacionais vistos por um índice (uma ferramenta) construído com base nos padrões da avaliação externa. Segundo o agente implementador de nível macro da Seduc, coordenador do Prêmio Nota Dez:

\begin{abstract}
[...] o que acontece? Nestes 25\% é que ele transformou em 18 para a educação, cinco para a saúde, dois para o meio ambiente. Antes do governo Cid Gomes, esses 25\% eram distribuídos praticamente [de forma igualitária]. E só ia para os grandes municípios. Hoje, com esses 18\% aqui, tem município desse aqui que dobrou o seu ICMS com o resultado na educação. É o principal meio de recurso - é o resultado da educação. E aí, para o prefeito que entende isso aí, e de vez em quando eles são chamados para mostrar esses dados aí... E ele, se ele realmente tiver interesse em dobrar o ICMS dele, ele vai cair em cima do secretário de Educação e vai dizer: "olha, vamos, vamos"... É assim que se faz, é assim que se alcança. Porque tem toda uma política por trás disso, certo?
\end{abstract}

Verifica-se que esse instrumento envolve todos os prefeitos do estado, tornando-os parte do conjunto de atores que têm interesse na implementação do Paic. O Prêmio Nota Dez, que premia as escolas que alcançam metas, é outro desses incentivos que se comportam como instrumentos. De acordo com burocratas cearenses de nível macro, o Prêmio Nota Dez gera capital político para o prefeito. Pode-se assim inferir que se trata de instrumento que implica esse dirigente na implementação do Paic, para além do interesse financeiro advindo da divisão da quota-parte do ICMS.

O Prêmio tem um capital político muito forte: prefeito vinha trazer as suas escolas... A escola é premiada, pega um prêmio, um troféu, uma placa, leva para dentro do município e diz "Olha aí, nós conseguimos os resultados!", recebe da mão do governador e é feita uma festa imensa com milhares de pessoas... Nós já chegamos a colocar até 10 mil pessoas num centro de eventos para essa premiação. Então, tem um capital político muito grande. (Coordenador do Prêmio Nota Dez, na Copem) 
[...] tem o Prêmio Escola Nota Dez - então, além de ter dinheiro, premiação e recurso de dinheiro envolvido, tem todo um evento, sabe, um momento... Parece um Oscar daqui do Ceará, sabe? Vem o Ministério da Educação, o governador... E tudo aquilo ali significa para um prefeito, para uma escola, aquele momento ali de se chegar no topo, no centro de eventos com uma plateia ali com 2 mil pessoas, 3 mil pessoas e chamar o prefeito e depois sair em todas as mídias e jornais aí... Isso tem impacto, né? (Coordenador do Eixo de Avaliação Externa, Copem)

A fala do coordenador do prêmio evidencia que esse instrumento oferece ferramentas, como os critérios de premiação, que incentivam cada município a elevar os resultados de todas as suas escolas, evitando que haja algumas com excelentes resultados, e outras nas quais as crianças não aprendam.

As escolas que concorrem à premiação têm que estar com pelo menos $70 \%$ dos alunos em nível desejado de escala de alfabetização. A rede do município tem que estar aí, senão ela nem entra. Ela pode ser a melhor escola do estado, mas, se a rede, aquele município, não estiver com pelo menos $70 \%$ dos alunos no desejável, a escola do município está fora. Ela não participa. Então, antes de olhar para a escola, tem que olhar para a rede. Se quiser a escola premiada, você tem que levar $70 \%$ dos meninos para o desejável.

O prêmio apresenta também um índice, aqui interpretado como uma ferramenta voltada para a equidade, que incentiva as escolas a melhorarem os resultados das crianças com mais dificuldade. Busca, portanto, regular o ensino de modo a incidir na redução da reprodução da desigualdade escolar, fazendo com que não seja vantajoso recorrer a práticas meritocráticas segundo as quais investe-se mais naquelas crianças que têm mais facilidade. A introdução desse critério ocorreu em 2011, após a percepção, pela Secretaria, de que muitos municípios estavam recorrendo a tais práticas. Foi uma correção de percurso, da qual se entrevê que essa medida, o prêmio, havia gerado repercussões negativas por gerar ações produtoras de desigualdade. Portanto, trata-se de uma medida capaz de criar e reconfigurar interesses.

No caso da equidade, criou-se uma barreira, o IDE [Índice de Desempenho da Escola]. No IDE é composto por taxa de participação, proficiência da escola e o fator chamado Fator para Ajuste da Universalização da Aprendizagem. O que esse fator faz? Esse fator pega a quantidade de alunos que está nos piores índices e os que estão nos melhores. A escola que vai deixando aumentar o percentual de alunos nos piores índices, o IDE dela vai sendo puxado para baixo. As que vão levando menos alunos nos piores índices, o IDE dela vai subindo. (Coordenador do Prêmio Nota Dez)

Como também tem um outro índice que é o IQE, que é índice que vai para os prefeitos que também tem fator de redução, à medida que se tem crianças nos níveis mais baixos, há uma redução daquela nota, tanto no prêmio como no cálculo do ICMS, tem esse índice que calcula o percentual de crianças naqueles níveis, né? Então assim, muita indução. (Ex-coordenadora da Copem, de 2007 a 2013) 


\title{
REGULAÇÃO DAS ESCOLAS/REDES DE ENSINO: TENSÕES, CONFLITOS E MEDIDAS PARA NEGOCIAÇÃO
}

Ribeiro (2012) não entrevistou professores, razão pela qual não é possível identificar precisamente conflitos próprios dos processos de regulação do município em questão. As falas das gestoras da escola visitada indicam concordância com as medidas e instrumentos adotados na rede.

No Paic, no que concerne ao instrumento de avaliação externa, embora reconhecendo sua importância para o processo de ensino e aprendizagem, a agente implementadora de nível micro de Fortaleza apresenta críticas a seu caráter exaustivo. Caracteriza a avaliação como um instrumento que, devido às especificidades de suas técnicas e ferramentas, demanda uma atenção e um tempo de trabalho excessivos. Critica ainda as muitas avaliações realizadas.

\begin{abstract}
As avaliações externas? Pois é... [risos]. Eu tenho um pouquinho de problema com elas. Eu entendo a importância delas: você vai avaliar uma rede, você precisa de uma avaliação grande. Mas eu acho que está tendo um excesso. A gente faz muita avaliação! E a gente tem que fazer a avaliação que já demora um tempo, que é o momento de aplicação, e, depois, a gente tem que corrigir esta avaliação em sala, o que já demora mais um tempo. E a gente faz isso todo mês, e é muito cansativo. Eu acho que, às vezes, acabo deixando de trabalhar outra coisa que é mais importante, porque eu tenho que fazer a correção da avaliação. Eu acho que as avaliações me ajudam a compreender de modo mais objetivo o que eu tenho que ensinar e o que os alunos têm que compreender. Como é que ele tem que dominar um conceito para resolver uma determinada questão. Eu gosto das avaliações externas. Mas eu acho que está tendo um excesso, né? (Professora de quinto ano, escola 2, Fortaleza)
\end{abstract}

Outra burocrata de nível micro, de outra escola de Fortaleza, apresenta um depoimento ambíguo em relação à avaliação externa, demonstrando, mais uma vez, tratar-se de um instrumento que suscita tensões. Por ela, não haveria avaliação externa, porque um exame não é capaz de indicar o que cada aluno sabe em sua completude, embora reconheça a seriedade e relevância do instrumento para si mesma e para a cidade.

A avaliação, por mim, não haveria mais. Essa coisa de medir... Mas eu sei que precisa. Eu vejo como uma faca de dois gumes. É um campeonato. Na hora, o aluno pode estar apto ou pode dar um branco. O Spaece [Sistema Permanente de Avaliação da Educação Básica] é um medidor. É uma avaliação externa. Me preocupo porque é importante para mim, para a cidade. Que nossa educação esteja ascendente. Mas não pego um assunto porque está na avaliação externa. Não vou me prender a isso. Spaece é uma coisa séria. Veio trazer para os profissionais mais responsabilidade. E o aluno é uma vida. (Professora do terceiro ano, escola 1, Fortaleza)

Uma professora de quinto ano revela que a aplicação do Spaece gera ansiedade e nervosismo, pois se configura como uma medida do seu trabalho.

Para mim, não deixo de ficar ansiosa, nervosa. Porque é um... é o resultado do meu trabalho do ano. Vai estar lá o resultado do meu trabalho. Tanto é o resultado da aprendizagem dos alunos como eu vejo ser o resultado do meu trabalho. Então, tanto a nota ou valor ou conceito que eles vão tirar lá vai refletir no meu trabalho. Poxa vida, esse é meu trabalho. Então, eu fico ansiosa, eu fico nervosa... "Puxa, lá vem o Paic." Mas não passo isso para os meus alunos, né? E nem deixo isso atrapalhar meu trabalho. É algo assim bem particular, mas que não atrapalha meu trabalho. 
Os depoimentos acima apresentam críticas e, ao mesmo tempo, indicam reconhecimento do valor da avaliação externa na regulação do ensino e da aprendizagem: uma evidência do poder desse instrumento na coordenação das ações dos agentes pelo cumprimento dos objetivos do Paic.

Depoimentos de gestores de nível macro indicam seu conhecimento das tensões que envolvem os distintos níveis federados que se unem em torno do Paic e, também, que adotam medidas visando a dirimi-las. A dirigente estadual cearense responsável pela implementação do Paic em 2007 afirmou que, para a implementação desse programa nos municípios, os líderes da Seduc buscaram realizar uma mudança na forma de se compreender a relação hierárquica entre as Crede e os municípios. Segundo ela, o discurso que faziam, com líderes, para as Credes era: "nós não temos ascendência em relação aos municípios, estamos em uma relação horizontal, então vamos descer do saltinho, não tem ninguém mandando em ninguém aqui”. Ela afirma que essa forma de qualificar a interação entre as equipes da Secretaria Estadual e as equipes dos municípios foi uma medida que facilitou o engajamento das Secretarias Municipais de Educação. O que, por sua vez, também favoreceu a interação com as escolas. Para ela, os técnicos das Crede são "representantes da Secretaria nos municípios", "eles têm a tarefa de fortalecer".

Para a tese de Ribeiro (2012, p. 295), técnico da Secretaria de Educação de Marília informou que os dirigentes municipais da educação buscam estabelecer parceria com as escolas, razão pela qual conseguem uma boa interação.

\begin{abstract}
Acho que [uma razão para a boa relação com as escolas é] esse acompanhamento [...] que nós fazemos aqui também de ir até a escola realmente, não por aquela coisa de uma visita para detectar erros, não é isso. Ir até a escola para sentir o clima da escola, ouvir o professor, o coordenador e pensar junto com eles numa proposta específica para aquela escola. 0 cronograma dessas escolas nós realizamos. Caso a escola solicite, a gente vai até a escola no horário estipulado.
\end{abstract}

Nas duas experiências, os agentes implementadores de nível macro falam de relação de confiança como meio de dirimir resistências e tensões entre as diversas instâncias de implementação das políticas, criando ambientes propícios de adesão às orientações estabelecidas. No caso do Ceará, essas instâncias envolvem relações intergovernamentais (estado e municípios), que são por definição constitucional horizontais e autônomas. Os dados mostram que o Paic precisou lidar com a crença, entre agentes implementadores de nível intermediário, de que o estado estaria em uma posição hierárquica superior aos municípios, o que dificultava o estabelecimento de relações de parceria.

Segundo um dirigente estadual cearense, ex-secretário do Estado, para lidar com interesses dos agentes implementadores e dirigentes municipais, minimizando assim as crenças, práticas e conflitos que dificultariam a implementação do programa, os dirigentes e implementadores de nível macro do Paic recorreram ao que chamou de

[...] combinação equilibrada de apoio-incentivo. Se tivesse só o ICMS e o prêmio, e não tivesse, vamos dizer assim, as considerações pedagógicas do que é adequado, olCMS e o prêmio poderiam ter produzido muito movimento, mas em alguns lugares, alguns casos, talvez até movimentos numa direção errada. Se tivesse só apoio pedagógico, orientação, construção de uma visão do que é necessário aprender e não tivesse o ICMS e o prêmio, não teria havido movimento significativo a ponto de mudar o perfil do estado.

O aprofundamento da análise dos depoimentos de um número maior de agentes implementadores poderá jogar luzes sobre outras tensões presentes na implementação das iniciativas em tela. E também sobre as novas configurações de crenças e interesses decorrentes da sua implementação. 
A regulação das iniciativas analisadas, redes consideradas mais equitativas em termos de distribuição de conhecimento, está referenciada em um modelo de regulação híbrido, nem "puramente" burocrático, nem pós-burocrático, considerando-se os tipos ideais "Estado avaliador" e "quase-mercado" definidos por Maroy (2011) e Barroso (2005). Há evidências de que, diante da necessidade de implementar políticas voltadas às prescrições da nova Constituição de 1988, lançou-se mão de perspectivas que teoricamente são colocadas em tensão: apoio pedagógico ao professor e cobrança de resultados com base em avaliações externas, por exemplo.

Nas duas iniciativas há currículo centralizado, com detalhamento de competências e habilidades. Metas são estabelecidas e exigidas das escolas. Mas não há evidências de foco na autonomia pedagógica das escolas, como nos modelos pós-burocráticos.

\begin{abstract}
Nós não temos escolas que têm total autonomia para usar esse método, essa diretriz ou aquela diretriz. Quando você diz assim: "olha, nós vamos pensar nessa proposta". [Torna-se] um guarda-chuva para a rede inteira. [...] Hoje a proposta é a mesma, se sair do centro e for para lá [a periferia] a proposta, a capacitação dos professores, as condições da escola, até num bairro pobre, a condição é igualzinha. (Secretária de Educação do município estudado)
\end{abstract}

No Paic, verifica-se que a formação continuada é elemento relevante no modelo de regulação, uma forma de acompanhar e incidir sobre o processo pedagógico nas escolas. É organizada numa cadeia que envolve a Seduc, as Crede e os órgãos dirigentes municipais. Nos municípios são organizados momentos formativos com os professores buscando envolvê-los com o que se espera do ensino e da aprendizagem. Segundo o agente implementar de nível macro:

Há um sistema de consultoria que forma o formador estadual. E aí, este formador estadual multiplica nas macrorregiões. O que são as macrorregiões? São polos onde estão mais de uma Crede. Às Crede, correspondem alguns municípios. [...] Ali estaria um formador do estado, bolsista [...]. Ele dá esta formação recebida pelo consultor para o formador municipal. E aí este formador municipal também recebe bolsa nossa [para atuar junto às escolas].

Em Fortaleza, professores entrevistados afirmam a existência de formação continuada, que ocorre mensalmente no distrito, e confirmam sua participação. Alguns trazem evidências de que o foco da formação é o conteúdo dado em sala de aula, presente no material didático distribuído pelo Paic. Uma professora relata que as reuniões formativas tratam da relação entre as metas das escolas, que conteúdos devem ser trabalhado e como.

A minha meta é alfabetizar $100 \%$ dos alunos. Somos cobradas. A reunião de formação [do distrito, trabalha com metas]. Para essa última reunião de formação, a meta era de 60\%. Há duas formações por mês. Uma da secretaria e outra com a coordenadora pedagógica. A formadora da rede fala como utilizar o livro do Paic. As atividades norteadoras. Como fazer. (Professora do primeiro ano, escola Fortaleza)

Tem a formação no distrito. Trabalham os livros que trabalhamos na sala de aula (Professora do segundo ano, escola Fortaleza)

A formação é organizada pelo distrito. Parte da SME, e depois o distrito. A formação ocorre todo mês. Costumo ir. (Professora do quarto ano, escola Fortaleza) 
Temos formação no distrito, uma vez por mês. Falam dos conteúdos. Bate com os conteúdos que estão sendo dados na sala de aula. Porque tem acompanhamento pelos conteúdos dos livros didáticos. [A questão da formação é] como você trabalharia tal conteúdo na sala de aula para que o aluno tenha um aprendizado satisfatório? (Professora do quinto ano, escola Fortaleza)

No âmbito do Paic, para todos os municípios do estado são distribuídos materiais didáticos estruturados e um kit com livros de literatura infantil produzido no estado. Nas escolas pesquisadas em Fortaleza, notou-se uma grande adesão dos professores ao que propõe o material didático distribuído pelo Paic. Evidências de que o material didático se constitui em uma técnica bem-sucedida, pelo menos nessas escolas, que vincula o ensino e aprendizagem, o currículo e o padrão de resultados esperado. A professora que fez algumas críticas mostrou, também, valorizar o material.

Particularmente, eu gosto do Paic. É um material assim [...] bem direcionado ao conteúdo e necessidade do aluno naquele nível, naquele ano, sabe? Algo assim mais... que prático. Eu acho melhor que o material didático, que os livros didáticos, sabe? Porque os livros didáticos, os textos são enormes, as questões são gigantes para responder. Enquanto o Paic, tem os textos básicos, necessários para o aluno aprender. (Professora do quinto ano, escola 1, Fortaleza)

Eu gosto muito do [livro] do Paic. Ele é didático. Tem muitas histórias que eles [os alunos] conhecem bastante. [...] É mais história daqui. Do Ceará. As atividades são bem sequenciais. Faz com que fixem mais. (Professora do primeiro ano, escola 1, Fortaleza)

Eu gosto muito de trabalhar com o material do Paic. Questão dos gêneros textuais, muito bom. Todo mês tem três ou quatro gêneros textuais. (Professora do quinto ano, escola 1, Fortaleza)

Uso o material do Paic para planejar, material bom. Uso o PNLD também. [...] O Paic é muito popular. A fala se adequa à realidade. São cabíveis, familiares, comuns. Tem o lado periferia. (Professora do terceiro ano, escola 1, Fortaleza)

Sim, eu gosto do Paic. Eu acho o Paic mais objetivo que o PNLD. As atividades do PNLD são mais abertas. O Paic é mais direcionado. Então, de um modo mais geral, eu gosto. Tem alguns problemas... Por exemplo, tem questões aqui que, quando você vai olhar o gabarito, eu não concordo com o gabarito. [...] Aqui diz que é o item B; mas não é o B, é o C. E aí vai ficar o item C. (Professora do quinto ano, escola 2, Fortaleza)

Em Fortaleza, a rede é dividida por distritos regionais, e superintendentes lotados nesses distritos visitam permanentemente as escolas de sua jurisdição. Entrevista com o diretor do distrito responsável por uma das escolas pesquisadas e agentes de nível intermediário indicam o papel desse órgão dirigente na coordenação das ações dos professores nas escolas.

Sim! Temos o acompanhamento nas escolas. [todos os cinco respondentes do distrito respondem em coro]. Na primeira formação do coordenador pedagógico, trabalha-se a rotina do professor. O superintendente também acompanha a escola. Se o superintendente vê que um professor não está seguindo a rotina [definida no Paic para a sala de aula], a orientação é tomar decisões in loco. 
Temos também um sistema para o acompanhamento da gestão escolar. O Sage. Ele é alimentado pelo superintendente. Há questões que se responde com sim ou não. Por exemplo: o professor segue a rotina, sim ou não. Fizemos esse ano uma operação para transformar o não em sim. Elaboramos um instrumento de acompanhamento para o coordenador pedagógico. O coordenador preenche e o professor assina. Temos a perspectiva de colaborar. Mas também de dizer: "professor, seria melhor fazer assim". Numa recente reunião, elencamos as escolas que estavam com fitinha vermelha, laranja no braço. Fizemos uma "junta pedagógica" para propor ações para essas escolas. Fizemos um plano de ação. Estamos acompanhando de perto uma das escolas que está com resultados muito baixos na avaliação externa. Já fui lá três vezes. Essa junta é formada por vários profissionais, o superintendente, os formadores (que tem o olho sobre o professor), o pessoal da ampliação da jornada.... Estamos com o projeto "Abrace essa Escola". (Diretor de distrito, com participação de equipe de formadores e superintendentes responsáveis pela escola 1 pesquisada em Fortaleza)

As escolas são, conforme se depreende dos dados acima, acompanhadas pela evolução dos resultados educacionais, mas também pelo tipo de prática pedagógica que estão realizando.

\section{CONSIDERAÇÕES FINAIS}

Este texto trata de duas iniciativas governamentais implementadas em dois sistemas educacionais de contextos distintos: uma municipal, desenvolvida na região Sudeste, e outra numa rede estadual do Nordeste, ou seja, em regiões com profundas diferenças do ponto de vista socioeconômico e cultural. Apesar disso, vários são os pontos de convergência entre elas: foco na melhoria da qualidade da educação e na alfabetização na idade certa, enfrentamento da desigualdade escolar, continuidade das experiências num período de mais de dez anos, poder executivo que protege as decisões dos dirigentes e agentes implementadores de nível macro, perfil de seus dirigentes e agentes implementadores de nível macro e o modelo de regulação que as rege.

Esse modelo de regulação faz uso de medidas educativas que estão teoricamente em tensão. Embora haja currículo unificado e centralizado e padrão de desempenho estabelecido por avaliação externa (medidas típicas dos modelos pós-burocráticos), não há incentivo à autonomia pedagógica das escolas, diferenciando-se, nesse aspecto, dos modelos pós-burocráticos de Maroy (2011) e Barroso (2005), corroborando, assim, o estudo do Cenpec (BATISTA et al., 2015) e de Ribeiro (2012).

Adotam-se medidas educativas - instrumentos, técnicas e ferramentas (LASCOUSMES; LES GALÈS, 2012) - destinadas a instituir vigilância do sistema sobre as interações e práticas dos profissionais da educação e a conduzir as ações dos dirigentes municipais (no caso do Paic), que tornaram o comportamento desses atores "orientado" para os objetivos previstos. Trata-se de um modelo que conduz experimentações de governança visando ao que os gestores denominam melhoria da qualidade da educação, sendo que essa noção de qualidade se mostra vinculada a padrões que indicam os termos da distribuição do conhecimento que é definido como relevante e também à perspectiva da promoção da equidade intraescolar e sistêmica. Dessa relação entre padrões e vigilância sobre as ações, surgem novas medidas educativas visando a correções ou reenquadramento das interações e ações de agentes implementadores. Esse resultado converge com Crahay (2000) que trata de requisitos para o alcance da equidade na escola.

No Paic, esses instrumentos se mostram incorporados nas práticas cotidianas, mas não sem tensões. Professores, ao mesmo tempo que reconhecem a importância dos resultados das avaliações externas para o ensino, consideram que se gasta tempo demais com essas avaliações; que suas técnicas e ferramentas exigem um trabalho exaustivo e que simplificam o que os alunos têm a mostrar em termos de aprendizagem. 
Importante destacar os resultados do uso de instrumentos voltados para a mediação das interações entre os entes federados: segundo os depoimentos, as ferramentas que orientam a divisão da quota-parte entre os municípios e o Prêmio Nota Dez implicam os prefeitos na implementação do Paic, levando-os a fortalecer a capacidade de gestão das Secretarias de Educação. Para além do interesse por mais recursos financeiros, os prefeitos angariam, por meios simbólicos, nos eventos de premiação e decorrências, poder político junto a seus pares e eleitores.

A literatura sobre implementação de políticas públicas e Sociologia das Regulações afirma que, quando se diminui a distância entre a prescrição e a implementação, há necessariamente influência sobre crenças, interesses, conhecimentos e formas de comunicação. E que equidade, no tipo de sociedade em que vivemos, não se alcança sem enfrentamento de conflitos. Com base nesses apontamentos, pode-se concluir que as medidas educativas e instrumentos adotados pelas iniciativas aqui analisadas foram capazes de realizar mudanças. Novas pesquisas poderão jogar luzes sobre que tipo de novas crenças e conhecimentos surgiram e como se reconfiguraram os interesses em torno da implementação das iniciativas governamentais aqui analisadas.

\section{AGRADECIMENTOS}

Agradecemos à Rede de Estudos sobre Implementação de Políticas Públicas Educacionais (Reippe), que tem apoiado esta pesquisa e permitido instigantes discussões sobre a temática da implementação das políticas educacionais.

Este artigo foi elaborado no âmbito da pesquisa "Implementação de políticas educacionais e equidade em contextos de vulnerabilidade social”, financiada pela Fundação de Amparo à Pesquisa do Estado de São Paulo (Fapesp), processo 2018/11257-6.

\section{REFERÊNCIAS}

BARDIN, L. Análise de conteúdo. Lisboa: Edições 70, 1977.

BARROSO, J. O estado, a educação e a regulação das políticas públicas. Educação e Sociedade, Campinas, SP, v. 26, n. 92, p. 725-751, out. 2005.

BATISTA, A. A. G.; MELLO, D. A.; FREITAS, P. F.; RIBEIRO, Vanda M.; GUSMÃO, J. B. de; BARRETTO, E. S. de S.; LUGLI, R. S. G.; NOVAES, L. C.; ALTENFELDER, A. H. Currículos para os anos finais do Ensino Fundamental: concepções, modos de implantação e usos. Estudos e Pesquisas Educacionais, São Paulo, v. 5, p. 15-72, nov. 2015.

BELLEI, C. Dificultades y resistencias de una reforma para des-mercantilizar la educación. Revista de La Asociacion de Sociología de La Educación, v. 9, n. 2, p. 232-247, 1988.

BONAMINO, A.; MOTA, M. O.; RAMOS, M. E.; CORREA, E. V. Arranjo Institucional de Implementação do PAIC e burocratas de médio escalão. In: LOTTA, G. (org.). Teorias e análises sobre implementação de políticas públicas no Brasil. Brasília: Enap, 2019.

BOURDIEU, P.; PASSERON, J. C. A reprodução: elementos para uma teoria do sistema de ensino. Lisboa: Veja Universidade, [1975].

BRASIL. Constituição (1988). Constituição da República Federativa do Brasil. Brasília, DF: Senado, 1988.

BRASIL. Lei n. 9.394, de 20 de dezembro de 1996. Estabelece as diretrizes e bases da educação nacional. Diário Oficial da União, Brasília, DF, 23 dez. 1996. p. 27833.

CEARÁ. Secretaria de Educação. Regime de colaboração para a garantia do direito à aprendizagem: o Programa Alfabetização na Idade Certa (Paic) no Ceará. Fortaleza: SEDUC, 2012.

CORREA, E. V. Accountability na Educação: impactos do Prêmio Escola Nota Dez na eficácia e equidade escolar do estado do Ceará. 2018. 207 f. Tese (Doutorado em Educação) - Pontifícia Universidade Católica do Rio de Janeiro, Rio de Janeiro, 2018.

CRAHAY, M. L'école peut-elle-être juste e efficace? De l'égalité des chances à l'égalité des acquis. Belgique: De Boeck, 2000. (Pédagogies en Développement).

CRUZ, M. C. M. T.; FARAH, M. F. S.; RIBEIRO, V. M. Estratégias de gestão da educação e equidade: o caso do programa aprendizagem na idade certa (mais PAIC). Revista on line de Política e Gestão Educacional, [S.1.], ago. 2020. Disponível em: https://periodicos.fclar.unesp.br/rpge/article/view/13904. Acesso em: 13 ago. 2020. doi: https://doi.org/10.22633/rpge.v24i3.13904.

DRAELANTS, H.; MAROY, C. L'analyse des politiques publiques: un panorama. Iaundê: Programme Supérieur de Spécialisation en Finances Publiques, 2007. 
DUBET, F. Les dilemmes de la justice. In: DEROUET, J. C.; DEROUET-BESSON, M. C. Repenser la justice dans le domaine de l'éducation et de la formation. Lyon: Peter Lang, 2009. p. 29-46.

GIUSTO, S.; RIBEIRO, V. M. Implementação de políticas públicas: conceito e principais fatores intervenientes. Revista de Estudios Teóricos y Epistemológicos en Política Educativa, v. 4, p. 1-10, 2019.

GUSMÃO, J. B.; RIBEIRO, V. M. Colaboração entre estado e municípios para a alfabetização de crianças na idade certa no Ceará. Cadernos Cenpec, São Paulo, v. 1, n. 1, p. 9-34, 2011.

KASMIRSKI, P.; GUSMÃO, J.; RIBEIRO, V. M. O Paic e a equidade nas escolas de ensino fundamental cearenses. Estudos em Avaliação Educacional, São Paulo, v. 28, n. 69, p. 848-872, set./dez. 2017.

KOSLINSKI, M. C.; RIBEIRO, E.; OLIVEIRA, L. X. Indicadores educacionais e responsabilização escolar: um estudo do "Prêmio Escola Nota Dez". Estudos em Avaliação Educacional, São Paulo, v. 28, n. 69, p. 804-846, set./dez. 2017.

LASCOUMES, P.; LES GALÈS, P. A ação pública abordada pelos seus instrumentos. Revista Pós Ciências Sociais, São Luís, v. 9 , n. 18, p. 19-44, jul./dez. 2012 .

LIPSKY, M. Street-level bureaucracy: dilemmas of the individual in public services. Nova York: Russell Sage Foundation, 2010.

MAROY, C. ; DEMAILLY, L. Les régulations intermédiaires des systèmes éducatifs en Europe: quelles convergences? Recherches Sociologiques, v. 35, n. 2, p. 5-24, 2004.

MAROY, C. Europe? Vers une régulation post-bureaucratique des systèmes d'enseignement en Europe? Sociologie et Sociétes, Montreal, v. 40, n. 1, p. 31-55, dec. 2008.

MAROY, C. Em direção a uma regulação pós-burocrática dos sistemas de ensino na Europa? In: OLIVEIRA, D. A.; DUARTE, A. (org.). Políticas públicas: regulação e conhecimento. Belo Horizonte: Fino Trato, 2011. p. 19-46.

MARTINIC, S.; ELACQUA, G. ¿Fin de ciclo? cambios en la gobernanza del sistema educativo. Santiago: UNESCO-OREALC-PUC, 2010.

MOTA, M. O. Entre a meritocracia e a equidade: o Prêmio Escola Nota Dez na percepção e atuação de agentes implementadores. 2018. 297 f. Tese (Doutorado em Educação) - Pontifícia Universidade Católica do Rio de Janeiro, Rio de Janeiro, 2018.

MULLER, P. L’analyse cognitive des politiques publiques: vers une sociologie politique de l'action publique. Revue Française de Science Politique, Paris, v. 50, n. 2, p. 189-208, 2000.

PADILHA F.; KASMISRKI, P. R.; CORRÊA, G. Z.; RIBEIRO, V. M.; BATISTA, A. A. G. Qualidade e equidade no ensino fundamental público do Ceará. Cadernos Cenpec, São Paulo, v. 3, n. 1, p. 82-110, dez. 2013.

RIBEIRO, V. M. Justiça na escola e regulação institucional de redes de ensino do estado de São Paulo. 2012. Tese (Doutorado em Educação) - Faculdade de Educação da Universidade de São Paulo, São Paulo, 2012.

RIBEIRO, V. M. Que princípio de justiça para a educação básica? Cadernos de Pesquisa, São Paulo, v. 44, n. 154, p. 1094-1109, out./dez. 2014.

SANTOS, W. G. Cidadania e justiça: a política social na ordem brasileira. Rio de Janeiro: Campus, 1979.

VIEIRA, S. L.; VIDAL, E. M. Construindo uma história de colaboração na educação: a experiência do Ceará. Educação e Sociedade, Campinas, SP, v. 34, n. 125, p. 1075-1093, dez. 2013.

\section{NOTA SOBRE AUTORIA}

Vanda Mendes Ribeiro fez entrevistas com gestores educacionais e escolares em Marília-SP para sua tese e, no Ceará, para estudo do Paic. Contribuiu na discussão conceitual sobre equidade, uso de instrumentos na ação pública e modelo de regulação, na elaboração das categorias a priori e na análise dos dados. Alicia Catalano Bonamino fez entrevistas com gestores educacionais e escolares no Ceará, para estudo do Paic. Aportou a discussão sobre o contexto brasileiro, a nova constituição e a equidade. Contribuiu na discussão conceitual sobre o uso de instrumentos na ação pública e na análise dos dados. Sergio Martinic contribuiu na discussão teórica sobre modelo de regulação e políticas educacionais, na definição das categorias a priori e na análise dos dados.

\section{COMO CITAR ESTE ARTIGO}

RIBEIRO, Vanda Mendes; BONAMINO, Alicia; MARTINIC, Sergio. Implementação de políticas educacionais e equidade: regulação e mediação. Cadernos de Pesquisa, São Paulo, v. 50, n. 177, p. 698-717, jul./set. 2020. https://doi. $\operatorname{org} / 10.1590 / 198053146982$

Recebido em: 18 NOVEMBRO 2019 | Aprovado para publicação em: 30 MARÇO 2020 